and trade commitments made at a World Trade Organization meeting in Doha, Qatar, in 2001. Bilateral trade agreements have since rendered those commitments unattainable.

Meanwhile, new drugs are needed for a wide range of diseases that affect poor people. But it's "not science that drives choices for scientific investigation," Orbinski says. "It's business values and return on investment. There are hundreds of promising compounds ... that will never make it through the pipeline."

That is where universities can play a role. "Scientists were so excited when we contacted them," said Jana Armstrong, director of the Drugs for Neglected Diseases Initiative in North America. The organization developed partnerships such as the Malaria Vaccine Initiative and ex- pects to have 6 to 8 new treatments for neglected diseases available by 2014 . Among its activities is searching out promising compounds or alternative uses for existing drugs. As an example of the latter, UBC's liaison office alerted pharmacy professor Kishor Wasan (who had been asked by Vancouver doctors to develop an oral form of amphotericin B) to the possiblility that the formulation could be used for visceral leishmaniasis, a fatal infection that attacks the spleen and the liver, and trypanosomiasis.

Meanwhile Wasan says his uncle Mumbai, India, physician Dr. Pravin Khullar - reinforced the need to have an oral form of the drug available in villages, where sufferers don't have ready access to intravenous treatment. "My uncle also says the WHO [World
Health Organization] estimates of 1.5 million cases a year are far too low," said Wasan, who was recently named Chair in Drug Delivery for Neglected Global Diseases, jointly sponsored at UBC by the Canadian Institutes of Health Research and the Vancouver biotechnology firm iCo Therapeutics Inc., which licensed his formulation.

University technology transfer offices are rethinking their role, and encouraging members to embrace global access principles, said Ashley Stevens, incoming president of the Deerfield, Illinois-based Association of University Technology Managers. That often involves engaging with international organizations such as the Bill and Melinda Gates Foundation and WHO. - Ann Silversides, CMAJ

DOI:10.1503/cmaj.090788

\title{
Long road to Sprinkles
}

$\mathrm{D}$

r. Stanley Zlotkin's invention was never going to be a money-maker. After all, it was designed to combat the debilitating iron deficiency experienced by children in the developing world. Not a lot of purchasing power there.

Zlotkin wanted to see the fruits of his labour - a powdered form of micronutrients sprinkled on food - used to benefit others. Unfortunately, when he approached his hospital's technology transfer office for help with patenting and developing the formula, he was turned

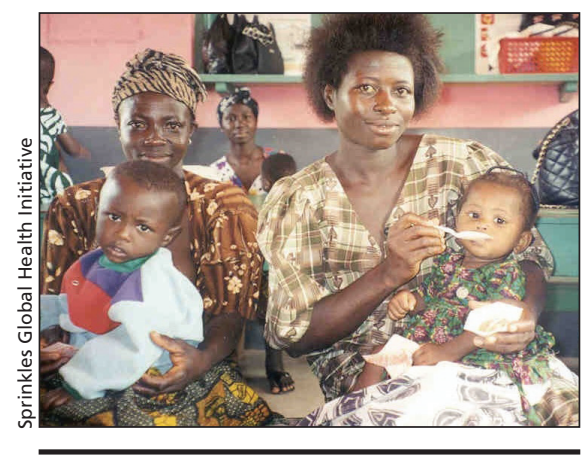

Ghanaian mother uses Sprinkles (in package) to add nutrients to her child's food. The micronutrient formula is used to combat iron and other deficiencies and the lifetime cost per child is $\$ 2$. down "because it was unlikely to make a profit," he told an Apr. 20-21 conference on Universities, Innovation and Global Medicine Access in Toronto, Ontario.

The Hospital for Sick Children in Toronto also forbade him from continuing to use the facilities in the hospital kitchen, where he was fine-tuning the formula in his off-hours.

But Zlotkin, now professor of pediatrics, nutritional sciences and public health at the University of Toronto and chief of gastroentereology and nutrition at the hospital, persisted. Today, his Sprinkles are manufactured in 6 facilities worldwide and benefit more than 4 million children in 18 countries; the lifetime cost per child is $\$ 2$.

Zlotkin's hospital has since had a change of heart. Several years ago, it joined with him to establish a nonprofit corporation, the Sprinkles Global Health Initiative, to further develop the product and increase distribution to more children in more countries, says Stuart Howe, director of corporate ventures for SickKids.

The early days were a hard slog. With no institutional support, Zlotkin decided to file a defensive patent in his own name. But because of that, he was perceived by some to have a conflict of interest. "There was always a feeling I was under a cloud of suspicion."

It was "difficult to make business decisions without the help of the tech transfer office," he added. The upside, though, was that official disinterest meant he had increased independence and speed in decision making.

To get Sprinkles to children, Zlotkin had to convince UNICEF to include the micronutrient in its catalogue for ordering food after an emergency. That required proof of efficacy and acceptability, as well as evidence that the formula could be produced in large volumes, at low cost, and easily distributed.

Convincing international aid agencies took time: "They were very risk averse. ... It was in-your-face advocacy." Regulatory approval was another hurdle as different countries variously considered Sprinkles a food, a drug or a natural food product. As well, several countries "for political or scientific reasons" insisted he repeat the research or conduct similar research. "I thought after I had one RCT [randomized controlled trial], that would be enough," he said. - Ann Silversides, CMAJ

DOI:10.1503/cmaj.090787 